\title{
A computational model of Suprachiasmatic Nucleus (SCN) for circadian rhythm modulation based on ion channel conductance and calcium dynamics
}

Hyoungkyu Kim, Jaeseung Jeong*

From Nineteenth Annual Computational Neuroscience Meeting: CNS*2010

San Antonio, TX, USA. 24-30 July 2010

The suprachiasmatic nucleus ( $\mathrm{SCN})$, the master biological clock of circadian rhythms, has been highly interested for biological rhythms in animals. Physiological and molecular biological studies [1-3] and computational modeling approach [4] have investigated channels contributing to circadian rhythms of spike firing frequency. The aim of this study was to investigate possible contribution of each channel to circadian rhythms using Hodgkin-Huxley-type model containing BK channel, potassium channel, sodium channel, and calcium

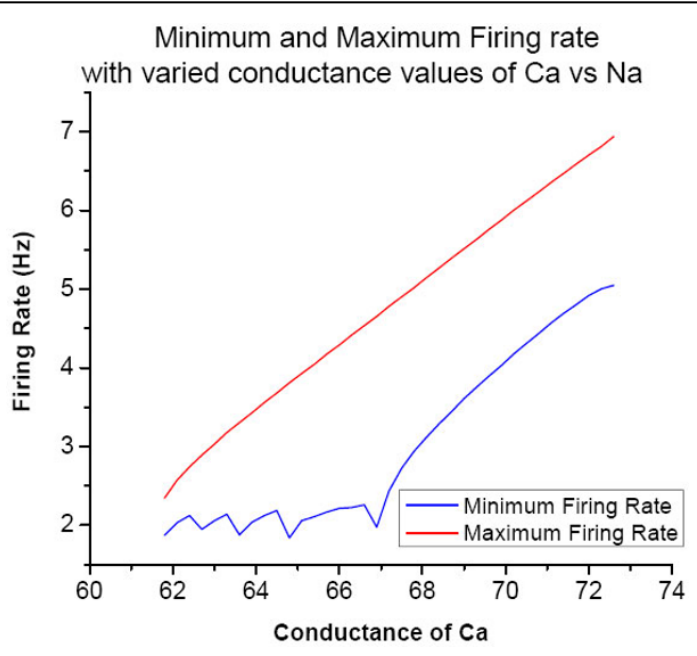

Figure 1 Minimum \& Maximum firing rates with varied conductance values of calcium and sodium channels.

* Correspondence: jsjeong@kaist.ac.kr

Department of Bio and Brain Engineering, KAIST (Korea Advanced Institute of Science and Technology), Daejeon, South Korea concentration oscillation. We found that the change in channel conductance modulated firing rates from high regular firing to low irregular firing with high sensitivity of the channel. In agreement with experimental data, the persistent sodium currents also highly contributed to modulation in spike firing frequency. The leak potassium currents and fast delayed rectifier currents exhibited to restrict the circadian firing range and regulation of interspike intervals. Most interestingly, the sinusoidal shape of the diurnal change in the channel conductance reproduced the change in diurnal firing rates. The calcium concentration oscillation and BK channel activity were examined to determine the synchronized circadian

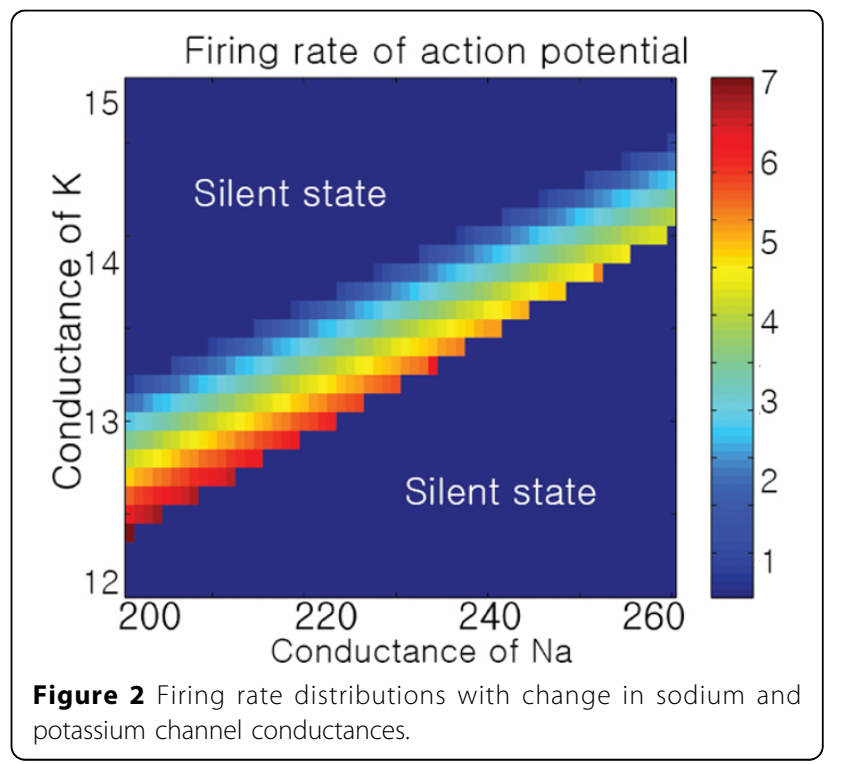


oscillation and phase shifting of firing rate in the neural network models structured by graph theory. We suggest that the model may be a guidance of channel properties in experimental conditions and be helpful to explain the circadian behaviors of SCN neurons.

Published: 20 July 2010

\section{References}

1. Jackson AC, Yao GL, Bean BP: Mechanism of Spontaneous Firing in Dorsomedial Suprachiasmatic Nucleus Neurons. Journal of Neuroscience 2004, 24(37):7985-7998.

2. Pennartz CMA, de Jeu MTG, Bos NPA, Schaap J, Geurtsen AMS: Diurnal modulation of pacemaker potentials and calcium current in the mammalian circadian clock. Nature 2002, 416:286-290.

3. Ikeda M, Sugiyama T, Wallace CS, Gompf HS, Yoshioka T, Miyawaki A, Allen CN: Circadian Dynamics of Cytosolic and Nuclear Ca2+ in Single Suprachiasmatic Nucleus Neurons. Neuron 2003, 38(2):253-263.

4. Choon Kiat Sim, Daniel BForger: Modeling the Electrophysiology of Suprachiasmatic Nucleus Neurons. J Biol Rhythms 2007, 22:445.

doi:10.1186/1471-2202-11-S1-P160

Cite this article as: Kim and Jeong: A computational model of Suprachiasmatic Nucleus (SCN) for circadian rhythm modulation based on ion channel conductance and calcium dynamics. BMC Neuroscience 2010 11(Suppl 1):P160.

\section{Submit your next manuscript to BioMed Central} and take full advantage of:

- Convenient online submission

- Thorough peer review

- No space constraints or color figure charges

- Immediate publication on acceptance

- Inclusion in PubMed, CAS, Scopus and Google Scholar

- Research which is freely available for redistribution

Submit your manuscript at www.biomedcentral.com/submit 